\title{
LOS PRINCIPIOS GENERALES DEL DERECHO EN LA FORMACIÓN DEL JURISTA. ESPECIAL REFERENCIA AL DERECHO URBANÍSTICO
}

\author{
Alberto Berrocal ACEDo \\ Abogado y doctorando \\ berrocalacedo@uma.es \\ Universidad de Málaga
}

\begin{abstract}
Resumen:
El presente trabajo trata de poner de relieve cómo pese a la importancia que poseen los principios generales del Derecho, por las funciones que cumplen, parecen haber perdido protagonismo tanto para el poder legislativo como para el poder judicial, así como para las Universidades, lo que redunda en perjuicio de la justicia, valor que debe servir de guía y al que ha de aspirar el Derecho. Junto a la exposición y análisis del problema, se proponen posibles soluciones.
\end{abstract}

Palabras Clave: principios de derecho, juristas, exceso de regulación, errores judiciales, formación docente.

\begin{abstract}
:
This paper tries to highlight how, in spite of the importance of the principles of law, due to the functions they satisfy, they seem to have lost prominence for the legislature and for the judiciary, as well as for universities. Is detrimental to justice, a value that should serve as a guide and to which the law must aspire. Beside the exposure and analysis of the problem, possible solutions are proposed.

Palabras clave: principios generales del Derecho, jurista, sobrerregulación, errores judiciales, formación docente.
\end{abstract}

Keywords: principles of law, jurist, overregulation, judicial errors, teacher training.

\section{Sumario:}

1. Introducción. 2. Problemática actual. 2.1. En el plano legislativo. 2.2. En el plano judicial. 2.3. En el plano universitario. 3. Conclusiones. 4. Bibliografía. 5. Webgrafía. 6. Índice de jurisprudencia. 


\section{Introducción}

El conocimiento de los principios generales del Derecho es fundamental para los juristas, pues vienen a cumplir, según se desprende del art. 1.4 del Código Civil ${ }^{1}$, al menos dos funciones esenciales, tal y como tiene dicho la doctrina ${ }^{2}$ : la función informadora del ordenamiento jurídico y la de fuente del Derecho de aplicación directa en caso de insuficiencia de la ley y la costumbre. Algunos autores ${ }^{3}$ hablan de una tercera función, la interpretativa o hermenéutica, si bien, como vienen a reconocer, ésta puede entenderse englobada en la primera a la que se ha hecho referencia.

Plenamente consciente de su importancia, el Tribunal Supremo ha dicho que "[l]os principios generales del Derecho, esencia del ordenamiento jurídico, son la atmósfera en la que se desarrolla la vida jurídica, el oxígeno que respiran las normas, lo que explica que tales principios «informen» las normas -art. 1. ${ }^{\circ}, 4$ del Título Preliminar del Código Civil- y que la Administración esté sometida no sólo a la Ley sino también al Derecho -art. 103,1 de la Constitución-." 4.

Si el papel de los principios generales es fundamental en todas las ramas del Derecho, dicha importancia es aún más palpable en el ámbito del Derecho Administrativo, en el que la incesante producción normativa desorienta al jurista que no los tenga bien presentes. Desde luego, tal y como advierte GARCÍA DE ENTERRÍA, parece imposible que haya alguien capaz de conocer todas las normas de distinto rango que se van introduciendo prácticamente a diario en el ordenamiento jurídico, y aunque hubiera quien pudiera hacerlo, de poco o nada le serviría, ya que de la aplicación mecánica de todos los preceptos no surge en ningún momento un sistema coherente, y aunque sí lo fuera, siempre gozarían de vigencia las archiconocidas palabras pronunciadas por VON KIRCHMANN en su discurso en Berlín, allá por el año 1847, conforme a las cuales "tres palabras rectificadoras del legislador convierten bibliotecas enteras en basura",

\section{Problemática actual}

Pese a lo narrado hasta ahora, puede observarse cómo últimamente los principios generales del Derecho parecen venir obviándose o, al menos, dejándose en un segundo plano, tanto por el poder legislativo, como por el poder judicial y las universidades.

\footnotetext{
${ }^{1}$ Cabe recordar que a tenor del art. 1.4 del Título Preliminar del Código Civil:

"Los principios generales del derecho se aplicarán en defecto de Ley y costumbre, sin perjuicio de su carácter informador del ordenamiento jurídico."

2 DÍEZ-PICAZO, L. (1983), "Los principios generales del derecho en el pensamiento de F. de Castro", Anuario de Derecho Civil, núm. 4, pp. 1263-1268, pág. 1264.

${ }^{3}$ En este sentido, siguiendo a ORTEGA ÁLVAREZ, se expresa MORENO LINDE, M. (2014): "Consideraciones sobre los principios del derecho administrativo y su vigencia y aplicación en el ámbito urbanístico", Revista andaluza de Administración Pública, núm. 90, pp. 127-170, pág. 129.

${ }^{4}$ STS (Sala de lo Contencioso-Administrativo, Sección 5a) de 18 de febrero de 1992 (RJ 1992/2904).

${ }^{5}$ GARCÍA DE ENTERRÍA, E. y FERNÁNDEZ, T. R. (2013): Curso de Derecho Administrativo I. $16^{\mathrm{a}}$ ed. Madrid: Civitas-Thomson Reuters, pág. 107.
} 
Ello, tal y como se pondrá de manifiesto seguidamente con la exposición de los problemas específicos que se plantean en cada ámbito, explicación que irá acompañada de ejemplos y de algunas propuestas que podrían ayudar a resolver la situación. Los ejemplos seleccionados versan sobre Derecho urbanístico porque los problemas a los que se viene aludiendo son especialmente evidentes en dicha materia $\mathrm{y}$, al mismo tiempo, es en dicha rama del Derecho donde se están produciendo algunas novedades muy positivas.

\subsection{En el plano legislativo}

En la labor legislativa, existe una tendencia muy clara que consiste en atajar cada problema jurídico con una norma creada $a d h o c$, lo que ha derivado en una exacerbada aprobación de normas de distinto rango (directivas, leyes, reglamentos, órdenes, etc.) que, la mar de las veces, además de fugaces, pueden resultar incluso contradictorias con otras, lo que nos parece del todo indeseable. De hecho, se trata de una realidad criticada no sólo por juristas, sino también por los agentes que se ven perjudicados por dicho fenómeno ${ }^{6}$.

Frente a esta situación de sobrerregulación existente no sólo a nivel estatal, sino también a nivel comunitario, no defendemos ni mucho menos la implementación en nuestro ordenamiento jurídico del que sería el polo opuesto, el common law, que es cierto que funciona en otros países, y lo hace precisamente asentándose en una serie de principios generales del Derecho que son perfilados constantemente por la jurisprudencia y por los juristas.

Lo que aquí se propone es, simplemente, brindar una mayor confianza a los principios generales del Derecho de la que actualmente se les concede, sin sustituir, eso sí, las reglas y prescripciones positivas, pues ello podría conducir a un excesivo casuismo o decisionismo normativo.

Es lo que han hecho, por ejemplo, los legisladores de Murcia y de Andalucía, cuando se han ocupado de la normativa urbanística. El primero, ha introducido en el art. 277.3 de la Ley 13/2015, de 30 de marzo, de ordenación territorial y urbanística de la Región de Murcia, una fórmula de proporcionalidad muy genérica pero plenamente aplicable a cualquier supuesto de restauración de la realidad física alterada ${ }^{7}$. El segundo, no sólo se

\footnotetext{
${ }^{6}$ Las noticias en este sentido se suceden en los últimos tiempos. A modo de ejemplo, se relacionan las siguientes:

SÁNCHEZ DE LA CRUZ, D.: (18 de septiembre de 2016): España es víctima de un 'tsunami' regulatorio: hasta 40 nuevas normas cada día [Web]. Disponible en: http://www.libremercado.com/2016-0918/espana-es-victima-de-un-tsunami-regulatorio-hasta-40-nuevas-normas-cada-dia-1276582517/

Consultado en 19/02/2017 a las 13:35.

INTEREMPRESAS: (20 de julio de 2016): El impacto económico de la sobrerregulación europea en el sector químico se duplica en los últimos diez años [Web]. Disponible en: http://www.interempresas.net/Quimica/Articulos/159979-El-impacto-economico-de-la-sobrerregulacioneuropea-en-el-sector-quimico-se-duplica-en-los.html Consultado en 19/02/2017 a las 13:25.

EL MUNDO: (s.f.): Leyes que frenan la innovación [Web]. Disponible en: http://www.elmundo.es/economia/2015/12/06/5662bfed22601d30528b4602.html Consultado en 19/02/2017 a las 13:55.

${ }^{7}$ Establece el mencionado art. 277.3 que:

"No procederá el establecimiento de la situación anterior cuando conlleve consecuencias más perjudiciales para el orden conculcado que su mantenimiento."
} 
ha positivado el principio de proporcionalidad en la protección de la legalidad urbanística, que aparece expresamente recogido en el art. 182.3 de la Ley 7/2002, de 17 de diciembre, de Ordenación Urbanística de Andalucía (en lo sucesivo, LOUA), sino que además ha sido ampliamente desarrollado por el art. 48.4 del Decreto 60/2010, de 16 de marzo, por el que se aprueba el Reglamento de Disciplina Urbanística de la Comunidad Autónoma de Andalucía (en adelante, RDUA) ${ }^{8}$. De esta forma, introduciendo el principio general en la norma y dando alguna directriz para su aplicación -ya se ha visto que en el caso de Murcia más genérica y en el de Andalucía más concreta-, se evita seguir alimentando la sobrerregulación.

\subsection{En el plano judicial}

En el ámbito del judicial, también se observan resoluciones muy discutibles y, de hecho, no pocas veces se producen agrias disputas en el seno del propio tribunal, por la interpretación, directa o indirecta, de las reglas aplicables por cada tribunal y en cada caso concreto (reglas entre las que han de estar también, en tanto fuente ineludible, los principios generales del Derecho).

A este respecto, va a citarse a modo de ejemplo, en primer lugar, una resolución de quien es el máximo garante de los derechos fundamentales en nuestro país y que, en nuestra opinión, debido a una palmaria omisión sobre los principios generales, no cumple en este caso con dicha función protectora. Se trata de la polémica STC número 188/2013 de 4 de noviembre (RTC 2013\188), que pasa por alto, a nuestro juicio, un

\footnotetext{
${ }^{8}$ Concretamente, preceptúa el art. 182.3 de la LOUA: urbanística aplicable, por resultar de imposible o muy difícil reposición." para la legalización, establece que: valorados, entre otros, los siguientes:

a) Superficie que exceda de lo autorizado.

b) Visibilidad desde la vía pública.

c) Incidencia de la obra edificada en el resto del conjunto edificatorio.

d) Solidez de la obra ejecutada.

e) Afección a barreras arquitectónicas.
}

“3. Regirán para la solicitud, tramitación y resolución de la legalización las mismas reglas establecidas para las aprobaciones o licencias que deban ser otorgadas. Reglamentariamente se establecerán los supuestos y condiciones en los que, con carácter excepcional y en aplicación del principio de proporcionalidad, quepa la legalización aún con disconformidades no sustanciales con la ordenación

Dicho desarrollo reglamentario, como decimos, se ha producido con el RDUA, que en su artículo 48.4,

“4. Con carácter excepcional y en aplicación del principio de proporcionalidad se podrá solicitar y acordar la legalización de las actuaciones aún con disconformidades no sustanciales con la ordenación urbanística aplicable, por resultar de imposible o muy difícil reposición. Como criterios a considerar para determinar la sustancialidad o no de la disconformidad con la ordenación urbanística, habrán de ser

No se aplicará este principio en los supuestos contemplados en el artículo 185.2 de la Ley 7/2002, de 17 de diciembre.

No podrán beneficiarse de la aplicación de este principio los responsables de la infracción que hayan sido sancionados por infracción urbanística grave o muy grave, impuesta por resolución firme.

La resolución que ponga fin al procedimiento, dictada previos los informes técnico y jurídico que habrán de valorar el grado de disconformidad existente, habrá de motivar la aplicación del principio de proporcionalidad, y establecer la indemnización sustitutoria al aprovechamiento urbanístico materializado sin título, en su caso.

Dicha indemnización deberá abonarse con independencia de las sanciones por infracciones urbanísticas que, en su caso, procedan, sin que, en ningún caso la aplicación de lo dispuesto en este apartado podrá reportar a las personas infractoras de la legalidad urbanística la posibilidad de beneficiarse de la reducción de la sanción que contempla el artículo 208.2 de la Ley 7/2002, de 17 de diciembre." 
principio tan básico como el de legalidad y, en íntima conexión con éste, la garantía previa instrucción de un procedimiento y el principio "nulla executio sine titulo". Para efectuar un análisis preciso de dicha resolución del exégeta de nuestra Carta Magna, conviene hacer un repaso a sus antecedentes, que son los siguientes:

Frente al domicilio del recurrente en amparo, de su esposa y de los dos hijos de ambos menores de edad-, se dictó por el Ayuntamiento de Madrid orden de demolición en fecha 23 de junio de 2005, orden que tenía su fundamento en tratarse de una construcción ilegal, ya que se levantaba sobre suelo no urbanizable, concretamente, sobre una vía pecuaria. La orden no fue ejecutada de forma voluntaria, por lo que el Ayuntamiento de Madrid dictó acuerdo de ejecución subsidiaria el 29 de noviembre de 2006, solicitó y obtuvo autorización judicial de entrada en domicilio del Juzgado de lo Contencioso-Administrativo núm. 7 de Madrid y, tras todo lo anterior, llevó a efecto la demolición el 18 de octubre de 2007.

Apenas dos días después de la demolición, esto es, el 20 de octubre de 2007, el recurrente en amparo ya había reconstruido totalmente su vivienda en idéntico emplazamiento. Ante esta situación, el Ayuntamiento, sin iniciar un nuevo procedimiento de protección de la legalidad urbanística, apoyándose en la orden de 23 de junio de 2005, requirió al recurrente que desalojara y demoliera la nueva construcción, y el 14 de abril de 2008 dictó acuerdo de ejecución subsidiaria, indicando que contra el mismo no cabía recurso alguno. Hecho lo anterior y a fin de ejecutar la orden de demolición de 23 de junio de 2005, el Ayuntamiento de Madrid solicitó, en fecha 2 de noviembre de 2010, nueva autorización judicial de entrada, siendo concedida (aunque demorándola hasta la conclusión del curso escolar de los menores) mediante Auto del Juzgado de lo Contencioso-Administrativo número 30 de Madrid de fecha 20 de abril de 2011, al entender que la orden de demolición y el acuerdo de ejecución subsidiaria derivaban de un expediente administrativo donde se habían respetado todas las prescripciones legales y que a dichas resoluciones administrativas no les afectan las alegaciones formuladas por el recurrente relativas a la construcción y a la aplicación de la Ley 2/2011 de la Comunidad de Madrid, de 15 de marzo, de la Cañada Real Galiana.

Dicha resolución fue recurrida en apelación ante el Tribunal Superior de Justicia de Madrid. El recurso se fundaba sustancialmente en la necesidad de un procedimiento previo, según el artículo 221.1 del Reglamento de Organización, Funcionamiento y Régimen Jurídico de las Corporaciones Locales, en que la orden de ejecución sustitutoria de 8 de febrero de 2010 hacía constar que contra la misma no cabía recurso alguno, lo que motivó que el recurrente no accionara contra la misma, circunstancia que le habría generado indefensión y, asimismo, se alegaba que la Ley de la Comunidad de Madrid 2/2011, de 15 de marzo, de la Cañada Real Galiana, había desafectado los terrenos de tal vía pecuaria a su paso por los municipios de Coslada, Rivas Vaciamadrid y Madrid, reconociendo la propia Ley que "en la actualidad el tránsito ganadero en el tramo que discurre por los tres mencionados municipios es nulo, encontrándose la vía pecuaria de hecho ocupada en buena parte por edificación de todo tipo y por un vial por el que circulan vehículos a motor", circunstancia que da buena prueba tanto de la ocupación colectiva como de la tolerancia de la Administración, siendo ilegal, a su juicio, proceder al derribo sin un previo proceso de concertación entre las partes interesadas previsto en la citada Ley autonómica. 
El recurso fue desestimado mediante Sentencia de fecha 8 de marzo de 2012, fundamentándose esta resolución judicial en que el acto administrativo de 23 de junio de 2005 da cobertura suficiente a la solicitud de desalojo y demolición, que la Ley de la Comunidad de Madrid 2/2011 no implica cambio en el planeamiento vigente y, por último, en que al iniciarse la reconstrucción de la infravivienda al día siguiente en que la Administración la demolió, se había incurrido en abuso de derecho, llegando incluso a deducir testimonio al Ministerio Fiscal por si los hechos fueran constitutivos de un delito de desobediencia grave a la autoridad.

Frente a la sentencia dictada en apelación, se solicitó el amparo del Tribunal Constitucional. El Ministerio Fiscal interesó el otorgamiento de amparo, entendiendo que "la Administración municipal debería haber dictado una nueva orden de demolición tras haberse reconstruido lo demolido, sin sustentarse exclusivamente en la anterior orden de demolición, omitiendo además respecto a la segunda demolición la autorización de la junta de gobierno local, concluyendo que el Ayuntamiento de Madrid no ha expuesto las razones por las que se apoya como acto de cobertura para el desalojo y demolición de la segunda construcción en la orden de 23 de junio de 2005, por la que se procedió a la demolición de la primera construcción, por lo que no se han respetado las normas procedimentales que permitirían incidir en el derecho de inviolabilidad domiciliaria, por lo que los pronunciamientos recurridos en amparo no satisfacen el canon de constitucionalidad exigido para la injerencia en el citado derecho fundamental".

Sin embargo, la Sentencia de la mayoría del Tribunal Constitucional, en respuesta al alegato de falta de procedimiento previo, afirma que:

"El antedicho control judicial de la apariencia prima facie de la legalidad extrínseca de la actuación administrativa para acordar la autorización de entrada domiciliaria es realizado por la Sentencia dictada en apelación por la Sala de lo Contencioso Administrativo del Tribunal Superior de Justicia de Madrid confirmando el Auto del Juzgado correspondiente de lo Contencioso-Administrativo, resolviendo, en contra de lo alegado por el recurrente en amparo, que la orden de demolición originaria, en virtud de la cual en ejecución sustitutoria, se procedió a la demolición de la construcción del recurrente, quien la reconstruyó al día siguiente en el mismo emplazamiento, no precisaba un nuevo pronunciamiento administrativo sobre el fondo del asunto del restablecimiento de la legalidad urbanística ni un nuevo acuerdo de la junta de gobierno municipal para solicitar nueva autorización de entrada pues el inicial acuerdo de la junta de gobierno municipal ya evidenciaba la voluntad de la Administración de ejecutar la resolución administrativa a cuyo fin acordaba solicitar la autorización judicial, así como la orden de demolición de 2005 constituye acuerdo de cobertura suficiente junto con la nueva orden de ejecución subsidiaria de 2008 para impetrar el auxilio judicial para la entrada en el domicilio a efectos de ejecutar la resolución administrativa. El derecho a la inviolabilidad domiciliaria no se ve vulnerado por los acuerdos administrativos anteriores pues la propia actuación del recurrente al reconstruir inmediatamente lo demolido por la primera orden administrativa municipal, provoca la inexistencia de solución de continuidad del procedimiento administrativo, no siendo legítimo impetrar el amparo constitucional por unos alegados e inexistentes defectos formales provocados por el propio recurrente, mediante una causa torpe, al reconstruir al día siguiente de la demolición lo que desde 
el inicio vulneraba la disciplina urbanística, siendo esta cuestión un acto firme y consentido por el recurrente, que no puede por la vía del recurso contencioso administrativo ni de este recurso de amparo reabrir el debate jurisdiccional de lo que debió en su caso ser alegado y discutido en un recurso contencioso administrativo contra el expediente de disciplina urbanística y no contra la pura ejecución del mismo, en la solicitud de autorización judicial, no habiéndose acreditado por el recurrente la pendencia de recurso contencioso administrativo alguno contra la orden de demolición de la construcción."

El voto particular no pasa por alto el trato dispensado por la Sentencia de la mayoría al examen de las garantías del procedimiento administrativo, señalando que "se advierte que la Administración municipal podría haber sido más escrupulosa, como con acierto recuerda el Ministerio Fiscal, en el respeto a las garantías del procedimiento administrativo, como era menester al estar comprometidos derechos tan sensibles. Así, por ejemplo, podría haber emitido una nueva orden de demolición aplicable a la segunda vivienda construida por el recurrente, en lugar de acudir a la de 23 de junio de 2005 sin exponer las razones por las cuales no era necesaria una nueva orden de demolición; podría haber dictado un nuevo acuerdo de ejecución subsidiaria previo a la solicitud de intervención judicial, en lugar de invocar reiterativamente al de 14 de abril de 2008, desestimado en primer término por el Juez competente; y podría haber indicado, sin inducir a errores, que el acuerdo de ejecución subsidiaria 14 de abril de 2008 era susceptible de recurso".

Desde la doctrina, XIOL RÍOS acusa a la sentencia aprobada de olvidar, en lo tocante a la exigencia de previa instrucción de procedimiento, el rigor formal que muestra para resolver las restantes cuestiones que se le plantean ${ }^{9}$, y CHAVES, por su parte, si bien considera que la solución alcanzada es correcta en este punto, formula una férrea crítica a la argumentación utilizada por el exégeta de nuestra Carta Magna ${ }^{10}$. Concretamente, valora negativamente el hecho de que la sentencia ponga el acento en este punto en el instituto de la causa torpe, propio del ámbito civil, sin argumentar ni hacer cita legal o jurisprudencial alguna, cuando, además, la causa torpe es propia de la calificación del negocio jurídico, no de un acto material como es en este caso la reconstrucción. A juicio de este autor, la sentencia podría haber optado por alguna de las siguientes vías: a) haber citado el principio general de que "nadie debe obtener beneficio de su propia torpeza", en lugar de aludir a la "causa torpe", de ámbito restringido al negocio jurídico; b) haber tenido en cuenta simplemente el principio de buena fe como regla de ejercicio de cualquier derecho, pues no actúa de buena fe quien reconstruye inmediatamente lo que

\footnotetext{
${ }^{9}$ XIOL RÍOS, C. (2013): "La legislación autonómica no puede introducir causas de suspensión de la ejecución de sentencias”, La administración práctica: enciclopedia de administración municipal, núm. 7: págs. $\quad$ [En $151-156 . \quad$ línea] aranzadi.aranzadidigital.es.jabega.uma.es/maf/app/document?docguid=I611 acc50da4d11e38e0b0100000 00000\&srguid=i0ad6adc60000015a091e1ddca2f86bff\&src=withinResuts\&spos=1\&epos=1\&displayid= \&publicacion $=\&$ clasificationMagazines $=\&$ fechacomun $=\&$ numeropub-tiponum $=\quad$ Consultado en 04/02/2017 a las 13:10

${ }^{10}$ CHAVES, J. R.: (17 de diciembre de 2013): Sobre la torpeza en el Tribunal Constitucional [Blog]. Disponible en: https://delajusticia.com/2013/12/17/sobre-la-torpeza-en-el-tribunal-constitucional/ Consultado en 01/02/2017 a las 17:35.
} 
le fue ordenado demoler; c) haber aplicado el art. 110.3 de la LRJPAC -cuyo equivalente actual es el art. 115.3 de la LPACAP-, a tenor del cual "Los vicios y defectos que hagan anulable un acto no podrán ser alegados por quienes los hubieren causado"; d) haber utilizado una argumentación jurídica sólida, en lugar de hacer un reproche más bien moral y, más concretamente, podría haber señalado que un acto administrativo firme no pierde ni su validez ni su eficacia por una actuación de mero hecho como en este caso sería la reconstrucción, o lo que es lo mismo y en palabras de este autor, que "el acto firme que ordenaba la demolición es un título jurídico para un efecto material, la demolición, de manera que cualquier acto de sentido contrario, inmediato o diferido, pondría de manifiesto la falta de ejecución de aquél y recobraría su vigencia".

Precisamente en una cuestión tan sensible como la relativa a los desalojos, se observa claramente cómo se guarda un doloroso silencio sobre los principios generales tanto por parte del legislador como por los órganos judiciales. Así, el primero ha aprobado una férrea normativa en materia de ejecución forzosa que no contiene la más mínima consideración ni referencia -ni siquiera en las exposiciones de motivos o en los preámbulos de las normas dictadas-, por ejemplo, a los "Principios Básicos y Directrices sobre los Desalojos y el Desplazamiento Generados por el Desarrollo" de la ONU. Los segundos también parecen desconocer dichos principios, además de otros principios generales del Derecho como el de necesidad o el de proporcionalidad, limitándose a aplicar el Derecho positivo de una forma totalmente alejada a la realidad social.

Sobre esto último, para ser justos, debe mencionarse que la antedicha STC 188/2013 de 4 de noviembre autoriza la entrada en el domicilio familiar a fin de que se demuela subsidiariamente por ser ilegal, pero demorando la misma, en aplicación del principio de proporcionalidad, hasta la conclusión del curso escolar de los menores que residían en el mismo, tratando de garantizar con ello sus derechos educativos ${ }^{11}$.

No obstante, lo habitual, como se viene señalando, es que no se tengan en cuenta principios generales que, sin duda, deberían influir en el desalojo, de manera que ha sido el Tribunal Europeo de Derechos Humanos el que, partiendo de algunos principios generales del Derecho, ha sentado una doctrina que ha venido a "poner orden" en cuanto a los desalojos derivados de órdenes de demolición de construcciones ilegales no

\footnotetext{
${ }^{11}$ A este respecto, permítase el inciso por la relevancia del asunto, entiendo que cabría plantearse una aplicación analógica del art. $158.6^{\circ}$ del Código Civil, cuyo ámbito de aplicación, a tenor de su último párrafo, queda reducido en principio a los procedimientos civiles o penales o bien a los expedientes de jurisdicción voluntaria. La importancia de este precepto viene dada, de un lado, porque manda al Juez que dicte, de oficio o a instancia del propio hijo, de cualquier pariente o del Ministerio Fiscal, en general, las disposiciones que considere oportunas, a fin de apartar al menor de un peligro o de evitarle perjuicios en su entorno familiar o frente a terceras personas y, de otro lado, porque le exige garantizar, además, que el menor pueda ser oído en condiciones idóneas para la salvaguarda de sus intereses, debiendo comunicarse por el Juzgado a la Entidad Pública, en caso de posible desamparo del menor, las medidas. En realidad, lo ideal, en mi opinión, sería reformar este artículo para que sea directamente aplicable también en el procedimiento contencioso-administrativo, ya que la limitación efectuada por la norma carece de sentido, toda vez que los intereses de los menores pueden verse claramente afectados como consecuencia del dictado de un acto administrativo.
} 
sólo en nuestro país, sino también en otros Estados de nuestro entorno que parecen compartir con nosotros este mismo problema ${ }^{12}$.

A tal punto llega el problema que, por ejemplo, la STSJ de Madrid (Sala de lo Contencioso-Administrativo, Sección $2^{\mathrm{a}}$ ) número 111/2014 de 5 de febrero (JUR 2014164858) acoge las pretensiones del recurrente de condicionar el desalojo de la vivienda ilegal a la previa puesta a disposición de una vivienda de realojo, simple y

\footnotetext{
${ }^{12}$ Esta doctrina se contiene en la STEDH de 24 de abril de 2012, caso Yordanova y otros contra Bulgaria (JUR 2012\142849), y en la STEDH de 17 de octubre de 2013, caso Winterstein y otros contra Francia (JUR 2013\321282), que viene a confirmar lo dicho por la primera. En estas resoluciones, el Tribunal Europeo de Derechos Humanos, valorando la necesidad y proporcionalidad de las medidas de desalojo, sienta los siguientes criterios:
}

a) Aun teniendo en cuenta que nos situamos en el ámbito de aplicación de políticas sociales y económicas, al estar implicado en estos supuestos el derecho a la vivienda junto con el derecho a la no injerencia en el domicilio, el amplio margen de apreciación nacional aparece modulado por el art. 8 $\mathrm{CEDH}$, que establece que " 1 . Toda persona tiene derecho al respeto de su vida privada y familiar, de su domicilio y de su correspondencia. 2. La autoridad pública solamente podrá injerirse en el ejercicio de este derecho en tanto en cuanto esta injerencia esté prevista por la ley y sea una medida necesaria, en una sociedad democrática, para la seguridad nacional, la seguridad pública, el bienestar económico del país, la defensa del orden y la prevención de los delitos, la protección de la salud o de la moral, o la protección de los derechos y libertades de los demás", ya que éste es decisivo para el disfrute efectivo de derechos íntimos; derechos de una importancia crucial para la identidad de la persona, su autodeterminación, su integridad psíquica y moral, el mantenimiento de sus relaciones sociales y su estabilidad y seguridad en la sociedad;

b) Adquiere una gran importancia el análisis del respeto a las salvaguardias de procedimiento disponibles para el individuo, de suerte que deberá examinarse si el proceso de toma de decisiones de las medidas restrictivas de derechos fue equilibrado y suficiente para satisfacer los intereses protegidos por el art. 8 $\mathrm{CEDH}$;

c) Considerando que la pérdida del hogar es una forma extrema de intervención en el derecho recogido en el art. $8 \mathrm{CEDH}$, cualquier persona en riesgo de sufrirla debe tener la garantía de que la medida será proporcionada y razonable, y de que esa proporcionalidad y razonabilidad las valorará un tribunal independiente;

d) Éste último elemento integra el derecho a que, cuando el demandante haya esgrimido argumentos sobre la proporcionalidad de la intervención en los procesos judiciales internos, los tribunales nacionales procedan a examinarlos en detalle y aportarán razones adecuadas para la estimación o desestimación de tales argumentos;

e) Si bien la injerencia del Estado en el derecho a la inviolabilidad del domicilio ex art. 8 CEDH puede tener una base legal en Derecho interno, es preciso justificar ad casum que es precisa la medida en una sociedad democrática para alcanzar un fin legítimo, por existir una necesidad social imperiosa;

f) En el juicio que corresponde realizar sobre ese particular, resulta obligado valorar diversos factores, entre otros que la recuperación se refiera, en su caso, a terrenos cuya ocupación ha sido tolerada desde tiempo atrás; que existan o no otros medios para resolver el problema; que concurra urgencia; que se atiendan suficientemente las necesidades de las familias afectadas y las consecuencias de su expulsión, señaladamente cuando se trata de situaciones de gran precariedad, $\mathrm{y}$;

g) Los supuestos en los que está en juego una comunidad entera y un asentamiento de larga duración deben ser tratados de forma absolutamente diferente de los asuntos referidos a la expulsión de un individuo de una propiedad que ocupe ilegalmente. 
llanamente, porque el ayuntamiento había condicionado la efectividad de la orden al previo realojo, pasando por alto -aparte de los principios antes mencionados- que en esta materia no rige el principio dispositivo ${ }^{13}$.

En ocasiones, incluso, parece desconocerse el propio contenido de principios generales del Derecho que podríamos tildar de básicos. En este sentido, puede destacarse cómo alguna Audiencia Provincial, contraviniendo lo que el intérprete de la Constitución tiene dicho acerca del principio de igualdad, decide no acordar la demolición de construcciones y edificaciones erigidas vulnerando la ordenación urbanística, incluso en parajes especialmente protegidos, por el mero hecho de que en el mismo entorno existen otras que no han sido derribadas. Así, la Sentencia de la Audiencia Provincial de Jaén (Sección 3a) número 255/2011 de 15 de diciembre (JUR 2012\68192) argumenta que al encontrarse la vivienda en un terreno donde existen otras edificaciones, el orden urbanístico infringido no se restablecería con la demolición de dicha vivienda, y sí se vulneraría el principio de igualdad. En la misma dirección, la Sentencia de la Audiencia Provincial de Jaén (Sección 2 $2^{\text {a }}$ ) número 128/2006 de 4 de septiembre (JUR 2007\124376) revoca la condena dictada por el Juzgado de lo Penal a demoler la construcción enjuiciada, consistente en vivienda unifamiliar sita en un Paraje declarado Bien de Interés Cultural, categoría zona arqueológica, y ello, por encontrarse "entre otras muchas" que "tampoco fueron demolidas". Con ello, como se viene apuntando, se transgreden los límites del principio de igualdad, delimitado por resoluciones como la STC 43/1982, de 6 de julio (RTC 1982\43) ${ }^{14}$, según la cual "el principio de igualdad ante la ley no puede transformarse en una exigencia de trato igual a todos fuera de la legalidad", o la STC 37/1982, de 16 de junio (RTC 1981\37), que afirma que "la equiparación en la igualdad, que por propia definición puede solicitar el ciudadano que se siente discriminado, ha de ser dentro de la legalidad y sólo ante situaciones idénticas que sean conformes al ordenamiento jurídico, pero nunca fuera de la legalidad, con extensión indebida a la protección de situaciones ilegales, ni tampoco para convalidar jurídicamente los defectos imputables a la siempre limitada eficacia en el plano de los hechos que las actuaciones de los poderes públicos desplieguen para el restablecimiento de la realidad física o jurídicamente alterada”.

\subsection{En el plano universitario}

Este problema de falta de atención a los principios generales del Derecho parece germinar en las propias Universidades. Así, entre las competencias que deben adquirir los estudiantes del Grado en Derecho durante sus estudios y que son exigibles para otorgar el título, cabe destacar, a los efectos del presente trabajo, la competencia número 27, que es una competencia específica consistente en la "capacidad para el manejo de

\footnotetext{
${ }^{13}$ Por el contrario, en esta materia impera el principio de legalidad, incompatible por regla general con el principio dispositivo. Así lo establece el art. 4.1 del Real Decreto Legislativo 7/2015, de 30 de octubre, por el que se aprueba el texto refundido de la Ley de Suelo y Rehabilitación Urbana, al señalar que la ordenación territorial y urbanística son funciones públicas no susceptibles de transacción, y en Andalucía, el art. 2 del RDUA dice que la disciplina urbanística se desarrollará de acuerdo con los principios de legalidad, oficialidad, entre otros.

${ }^{14}$ Ponente Tomás y Valiente.
} 
fuentes jurídicas (legales, jurisprudenciales y doctrinales) [sic] ${ }^{, 15}$. Como puede verse, se está dando por sentado que las fuentes del Derecho existentes son, única y exclusivamente, las primarias y las aclaratorias, obviándose las complementarias, entre las que se encuentran, junto a la costumbre, los principios generales del Derecho y, más concretamente, aquellos principios generales que no están positivados, como, por ejemplo, el de "qui potest plus, potest minus", o la propia proscripción del enriquecimiento sin causa.

Insistiendo en el valor formativo de los principios generales dentro de los estudios de Derecho, proponemos la efectiva implantación de fórmulas, instrumentos y mecanismos para hacer transversal y visible su operatividad. La innovación formativa podría pasar, así, por incrementar la carga docente de asignaturas de metodología o carácter horizontal, donde se estudien instituciones y principios comunes a todas las áreas, como superación de la fragmentación actual de los estudios y, quizás, de un excesivo apego a los postulados positivos por encima del auténtico conocimiento aplicativo de la Ley, en donde han de jugar un papel esencial, aunque entendemos que no excluyente, los principios generales informadores de nuestro ordenamiento jurídico.

\section{Conclusiones}

No proponemos nada que no esté ya inventado, sino que lo que se quiere fomentar con el presente trabajo es la recuperación de una forma de estudiar el Derecho que ha caído en el olvido y que parece estar incluso desprestigiada pero que, en nuestra opinión, es la que más puede acercar al jurista al ansiado principio de justicia material.

En este sentido, creemos que los principios generales del Derecho deben tener un papel más importante en el estudio del Derecho del que actualmente se les confiere. No se trataría solamente de introducir una mayor carga lectiva en relación con los mismos, sino, sobre todo, de transmitir un razonamiento jurídico por principios generales.

Resulta significativo, a este respecto, que las Facultades de Derecho que copan los primeros puestos en los rankings mundiales imparten el common law ${ }^{16}$, el cual, como por todos es sabido y así se ha puesto de relieve en este trabajo, se asienta sobre una serie de principios generales que se van perfilando constantemente por la jurisprudencia y la doctrina. Está claro que el método de enseñanza no es lo único, ni mucho menos, que conduce a estas Facultades a ocupar dichas posiciones, pero no es menos cierto que dicha forma de enseñar contribuye a estar en el máximo escalafón.

\footnotetext{
${ }^{15}$ UNIVERSIDAD DE MÁLAGA (s.f.): COMPETENCIAS Derecho [Web]. Disponible en (1 de febrero de 2017): https://www.uma.es/grado-en-derecho/cms/menu/informacion-grado/competencias/ Consultado en $02 / 02 / 2017$ a las $16: 00$

16 TOP UNIVERSITIES (s.f.): QS World University Rankings by Subject 2016 - Law [Web]. Disponible en: $\quad$ https://www.topuniversities.com/university-rankings/university-subject-rankings/2016/law-legalstudies Consultado en 18/02/2017 a las 13:15.
} 
En definitiva, si queremos tener mejores juristas, creemos que, en la formación de los mismos, habría que darles un mayor protagonismo a los principios generales del Derecho.

\section{Bibliografía}

DÍEZ-PICAZO, L. (1983), "Los principios generales del derecho en el pensamiento de F. de Castro", Anuario de Derecho Civil, núm. 4, pp. 1263-1268.

CANEDO ARRILLAGA, M. P. y GORDILLO PÉREZ, L. I. (2017): Los perfiles del jurista en el siglo XXI. Madrid: Editorial Civitas.

GARCÍA DE ENTERRÍA, E. y FERNÁNDEZ, T. R. (2013): Curso de Derecho Administrativo I. $16^{\text {a }}$ ed. Madrid: Civitas-Thomson Reuters.

RUOCCO, G. (2015): "Principios generales de derecho administrativo", Estudios de derecho administrativo, núm. 11, pp. 383-406.

MORENO LINDE, M. (2014): "Consideraciones sobre los principios del derecho administrativo y su vigencia y aplicación en el ámbito urbanístico", Revista andaluza de Administración Pública, núm. 90, pp. 127-170.

\section{Webgrafía}

CHAVES, J. R.: (17 de diciembre de 2013): Sobre la torpeza en el Tribunal Constitucional [Blog]. Disponible en: https://delajusticia.com/2013/12/17/sobre-latorpeza-en-el-tribunal-constitucional/ Consultado en 01/02/2017 a las 17:35.

EL MUNDO: (s.f.): Leyes que frenan la innovación [Web]. Disponible en: http://www.elmundo.es/economia/2015/12/06/5662bfed22601d30528b4602.html

Consultado en 19/02/2017 a las 13:55.

INTEREMPRESAS: (20 de julio de 2016): El impacto económico de la sobrerregulación europea en el sector químico se duplica en los últimos diez años [Web]. Disponible en: http://www.interempresas.net/Quimica/Articulos/159979-Elimpacto-economico-de-la-sobrerregulacion-europea-en-el-sector-quimico-se-duplicaen-los.html Consultado en 19/02/2017 a las 13:25.

SÁNCHEZ DE LA CRUZ, D.: (18 de septiembre de 2016): España es víctima de un 'tsunami' regulatorio: hasta 40 nuevas normas cada día [Web]. Disponible en: http://www.libremercado.com/2016-09-18/espana-es-victima-de-un-tsunamiregulatorio-hasta-40-nuevas-normas-cada-dia-1276582517/ Consultado en 19/02/2017 a las 13:35. 
TOP UNIVERSITIES (s.f.): QS World University Rankings by Subject 2016 - Law [Web]. Disponible en: https://www.topuniversities.com/university-rankings/universitysubject-rankings/2016/law-legal-studies Consultado en 18/02/2017 a las 13:15.

UNIVERSIDAD DE MÁLAGA (s.f.): COMPETENCIAS Derecho [Web]. Disponible en: https://www.uma.es/grado-en-derecho/cms/menu/informacion-grado/competencias/ Consultado en 02/02/2017 a las 16:00.

XIOL RÍOS, C. (2013): "La legislación autonómica no puede introducir causas de suspensión de la ejecución de sentencias", La administración práctica: enciclopedia de administración municipal, núm. 7: págs. 151-156. [En línea] http://0aranzadi.aranzadidigital.es.jabega.uma.es/maf/app/document?docguid=I611acc50da4d1 $1 \mathrm{e} 38 \mathrm{e} 0 \mathrm{~b} 010000000000 \&$ srguid=i0ad6adc60000015a091e1ddca2f86bff\&src $=$ withinRes $\underline{\text { uts } \& \text { spos }=1 \& \text { epos }=1 \& \text { displayid }=\& \text { publicacion }=\& \text { clasificationMagazines }=\& \text { fechacomu }}$ $\underline{\mathrm{n}=\& \text { numeropub-tiponum }}=$ Consultado en 04/02/2017 a las 13:10.

\section{6. Índice de jurisprudencia}

Tribunal Europeo de Derechos Humanos:

- Sentencia de 24 de abril de 2012, caso Yordanova y otros contra Bulgaria.

- Sentencia de 17 de octubre de 2013, caso Winterstein y otros contra Francia.

Tribunal Constitucional:

- Sentencia número 188/2013, de 4 de noviembre.

- Sentencia número 43/1982, de 6 de julio.

- Sentencia número 37/1982, de 16 de junio.

Tribunal Supremo:

- Sentencia de 18 de febrero de 1992.

Tribunales Superiores de Justicia:

- Sentencia del Tribunal Superior de Justicia de Madrid (Sala de lo ContenciosoAdministrativo, Sección $2^{\text {a }}$ ) número 111/2014 de 5 de febrero.

Audiencias Provinciales:

- Sentencia de la Audiencia Provincial de Jaén (Sección 3a) número 255/2011 de 15 de diciembre.

- Sentencia Audiencia Provincial de Jaén (Sección 2ª) número 128/2006 de 4 de septiembre. 